\title{
Association of whole blood copper, magnesium and zinc levels with metabolic syndrome components in 6-12-year-old rural Chinese children: 2010-2012 China National Nutrition and Health Survey
}

\section{Huidi Zhang}

China CDC https://orcid.org/0000-0001-9671-8401

\section{Qingqing Man}

Chinese Center for Disease Control and Prevention National Institute for Nutrition and Health

\section{Pengkun Song}

Chinese Center for Disease Control and Prevention National Institute for Nutrition and Health

\section{Siran Li}

Chinese Center for Disease Control and Prevention National Institute for Nutrition and Health

\section{Xiaobing Liu}

Chinese Center for Disease Control and Prevention National Institute for Nutrition and Health

\section{Lijuan Wang}

Chinese Center for Disease Control and Prevention National Institute for Nutrition and Health

\section{Yuqian Li}

Chinese Center for Disease Control and Prevention National Institute for Nutrition and Health

\section{Lichen Yang ( $\nabla$ yanglc@ninh.chinacdc.cn )}

https://orcid.org/0000-0002-2691-0411

\section{Research}

Keywords: MetS components; whole blood; copper; zinc; magnesium; Chinese children.

Posted Date: August 20th, 2020

DOl: https://doi.org/10.21203/rs.3.rs-31447/v2

License: (c) (i) This work is licensed under a Creative Commons Attribution 4.0 International License. Read Full License 


\section{Abstract}

Background: Copper (Cu), magnesium $(\mathrm{Mg})$ and zinc $(\mathrm{Zn})$ are essential elements that participate in a series of oxidative stress and inflammation pathways related to metabolic reactions. Many studies have analyzed the relationship between $\mathrm{Cu}, \mathrm{Mg}$ and $\mathrm{Zn}$ and metabolic syndrome (MetS) in adolescents and adults, but there have been few studies of children. We aimed to investigate the association of whole blood $\mathrm{Cu}, \mathrm{Mg}$ and $\mathrm{Zn}$ with MetS components in 6-12-year-old rural Chinese children.

Methods: A total of 911 children (51.2\% male, $48.7 \%$ female) aged $6-12$ years were enrolled from the 2010-2012 China National Nutrition and Health Survey. Basic characteristics, metals and MetS component parameters were collected. Multivariate logistic regression analysis was performed to examine the independent relationship between metals and the incidence of MetS components.

Results: Copper was positively associated with elevated waist circumference when analyzed alone $(\mathrm{OR}=2.00,1.18-3.28)$. Combined with $\mathrm{Zn}$, this association approached zero. For elevated triglyceride levels, the combination of low $\mathrm{Cu}$ and high $\mathrm{Zn}$ showed the opposite association with triglyceride relative to $\mathrm{Cu}$ alone $(\mathrm{OR}=2.21,1.18-4.13$ versus $\mathrm{OR}=0.33,0.16-0.65$, respectively), but was similar to the analysis of $\mathrm{Zn}$ alone $(\mathrm{OR}=2.12,1.10-4.10)$. There was no association between whole blood $\mathrm{Mg}$ and waist circumference. However, the presence of both high $\mathrm{Cu}$ and high $\mathrm{Mg}$ levels significantly increased the risk of waist circumference exceeding the standard value $(\mathrm{OR}=2.03,1.26-3.27)$. In addition, separate analysis of the distribution of $\mathrm{Mg}$ and $\mathrm{Zn}$ found no association with the risk of reduced high density lipoproteincholesterol (HDL-C); but high Zn combined with low Mg negatively associated with the risk of reduced HDL-C levels (OR=0.47, 0.28-0.77).

Conclusions: Both the single and combined effects of $\mathrm{Cu}, \mathrm{Mg}$ and $\mathrm{Zn}$ were associated with components of MetS. These results indicate the importance of combined analysis of multiple elements, and also provide new avenues for the early screening of MetS. The current results need to be further investigated in future work and other populations.

\section{Introduction}

Metabolic syndrome (MetS) is associated with a cluster of related risk factors of metabolic origin that promote the development of cardiovascular disease and increase the risk for development of type 2 diabetes [1]. Metabolic syndrome may be the result of the interaction of environmental, genetic and lifestyle factors. Currently, MetS is increasing worldwide and approximately $34 \%$ of the population meet the criteria for MetS; $33.9 \%$ of the Chinese population meet this criteria [2]. The prevalence of MetS is increasing rapidly and showing a trend of impacting younger age groups. In Chinese children, the prevalence of MetS increased from 2.3\% in 2004-2010 to 3.2\% in 2011-2014 [3].

Copper $(\mathrm{Cu})$, magnesium $(\mathrm{Mg})$ and zinc $(\mathrm{Zn})$ are all important trace elements involved in various metabolic pathways $[4,5]$. Copper and $\mathrm{Zn}$ play an important role in oxidative stress and inflammation $[6,7]$, as co-factors of antioxidant enzymes [8]. Magnesium is the second most abundant intracellular ion 
after potassium, and Mg deficiency is associated with several diseases, such as coronary heart disease and type 2 diabetes [9]. One hypothesis suggests that a key mechanism leading to MetS involves oxidative stress caused by redox imbalance [10]. Thus, metals may be related to the development of MetS. Several studies have found relationships between single metal levels, such as $\mathrm{Zn} \mathrm{[11],} \mathrm{Cu} \mathrm{[12]} \mathrm{and}$ $\mathrm{Mg}$ [13], and the incidence of MetS. Further evaluation of the relationship between multiple elements and MetS remains to be assessed, especially in children. Also, whole blood, which is a comprehensive indicator of the nutritional status of elements in vivo, is rarely used as a biological specimen, compared with plasma and serum samples. Some studies indicated that the concentration of elements in whole blood is higher than that in plasma or serum, and can more comprehensively reflect the exposure in the body $[14,15]$.

In this cross-sectional study, we investigated the correlation between whole blood $\mathrm{Cu}, \mathrm{Mg}$ and $\mathrm{Zn}$ and the risk of MetS components in Chinese children from the 2010-2012 China National Nutrition and Health Survey (CNNS).

\section{Material And Method}

\subsection{Subjects}

The study was based on data obtained from the 2010-2012 CNNS, which was a cross-sectional, nationally-representative survey. According to Green's rule of numbers of participants used to examine relationships, a reasonable sample size is greater than $50+$ $8 \mathrm{~m}$ (where $\mathrm{m}$ is the number of independent variables) for testing a multiple correlation [16]. In this study, the number of independent variables was 15 and the minimum sample size was 170 . We randomly selected 1008 participants (equally from females and males) from the 2010-2012 CNNS who were aged 6 to 12 years and from 72 rural areas, which all had complete physical detections and laboratory tests. Subjects were sampled by a multi-stage stratified random sampling method. All samples were reexamined after physical and biological data collection with the following exclusion criteria: 1) missing data for variables (excluded 33 samples); 2) data does not meet test standards (excluded 41 samples); 3 ) outlier for statistical analysis (excluded 23 samples). Due to the exclusion of certain samples, 911 samples were finally recruited in this study. All subjects and their guardians gave informed consent for inclusion before they participated in the study. The study protocol was approved by the Ethics Committee of the Institute for Nutrition and Food Safety, Chinese Center for Disease Control and Prevention (now known as the National Institute for Nutrition and Health, China CDC; file number 2013-018).

\subsection{Data collection}

Physical examinations were performed by trained medical staff following standardized procedures. Height was measured by a Seca 213 Portable Stadiometer Height-Rod with a precision of $0.1 \mathrm{~cm}$. Body weight was measured by a Seca 877 electronic flat scale with a precision of $0.1 \mathrm{~kg}$. During the measurements, the subject was required to take off shoes, hats, and coats, and females untied their braids to ensure the accuracy of measurements. Body mass index (BMI) was calculated as weight 
$(\mathrm{kg})$ /square of height $\left(\mathrm{m}^{2}\right)$. Waist circumference was measured two centimeters above the navel by a tape with a precision of $0.1 \mathrm{~cm}$. Systolic blood pressure (SBP, $\mathrm{mmHg}$ ) and diastolic blood pressure (DBP, $\mathrm{mmHg}$ ) were assessed in the right upper arm using a mercury sphygmomanometer. The blood pressure of each subject was the average of three measurements. Venous blood was collected from all subjects in the morning after 10-14 $\mathrm{h}$ of fasting, and each sample was divided between an anticoagulation tube and serum separator tube. Blood samples in serum separator tubes were promptly centrifuged at $3000 \mathrm{~g}$ for $15 \mathrm{~min}$, and divided into serum aliquots and frozen at $-80^{\circ} \mathrm{C}$ for subsequent assays. Serum fasting glucose (FG), high density lipoprotein-cholesterol (HDL-C), and triglyceride (TG) levels were measured by an enzymatic method using a Hitachi 7600 automatic biochemical analyzer (Japan). Whole blood Cu, Mg and $\mathrm{Zn}$ concentrations were measured by inductively coupled plasma mass spectrometry (NexION 350D, PerkinElmer) from the anticoagulation tube in Kinetic Energy Discrimination (KED) model.

\subsection{Definition of MetS and its components}

As the subjects in this study were aged 6 to 12 years, no consistent definition of MetS could be used in this analysis. We adopted a modified criteria for MetS from the American Academy of Pediatrics and International Diabetes Federation [17], which indicate MetS has the presence of $\geq 3$ of the risk factors. The MetS components were defined as follows: 1 ) obesity: waist circumference $\geq 95$ th percentile of children of the same age and gender, or BMI $\geq 95$ th percentile of children of the same age and gender; 2 ) hypertension: blood pressure $\geq 95$ th percentile of children of the same age and gender (fast identification: systolic BP $\geq 120 \mathrm{mmHg}$ or diastolic $\mathrm{BP} \geq 80 \mathrm{mmHg})$; 3) dyslipidemia: a. Reduced HDL-C (<1.03 mmol/L); or b. Elevated TG ( $\geq 1.47 \mathrm{mmol} / \mathrm{L}) ; 4$ ) hyperglycemia: $F G \geq 5.6 \mathrm{mmol} / \mathrm{L}$.

\subsection{Statistic analysis}

Statistical analyses were performed using SPSS version 19.0. The results of descriptive characteristics were expressed as average \pm standard deviation. The relationships among clinical indexes and the number of MetS components were analyzed using the Kruskal-Wallis test. Spearman correlation coefficients were applied to assess the relationship between metals and MetS components. The odds ratios (ORs) and $95 \%$ confidence intervals $(95 \% \mathrm{Cls})$ were determined by multivariate logistic regression to investigate the associations between MetS components and tertiles of whole blood metals. We categorized the level of whole blood $\mathrm{Cu}, \mathrm{Zn}$, the ratio of $\mathrm{Cu}$ to $\mathrm{Zn}$, and $\mathrm{Mg}$ into tertiles and used the lowest tertile as the reference. P-trend analysis involved treating the tertiles as a continuous variable in regression analyses. The combination of metals defined as low was a concentration $<50 \%$ of the range, and those defined as high was the concentration $\geq 50 \%$ percentage whole value. All statistical tests were two-sided and statistical significance was considered at $P<0.05$.

\section{Results}

\subsection{Characteristics of the study population}


This study examined 911 individuals (444 females, 467 males) with complete data on MetS components and whole blood $\mathrm{Cu}, \mathrm{Mg}$ and $\mathrm{Zn}$ concentrations. Basic characteristics of the subjects are shown in Table 1. There were gender-based differences in the comparison of clinical and biological indexes: the waist circumference, HDL-C and $\mathrm{Cu}$ concentrations, and $\mathrm{Cu} / \mathrm{Zn}$ ratio were higher in males, but the TG concentration was higher in females. We also analyzed these variables using different numbers of MetS components. We observed that age, BMI, height, weight, waist, rate of obesity, levels of $\mathrm{FG}$ and $\mathrm{Cu}$, the $\mathrm{Cu} / \mathrm{Zn}$ ratio and SBP exhibited an ascending trend, while HDL-C levels had a descending trend, with an increasing number of MetS components. We also examined the differences between groups defined as exhibiting different numbers of MetS components. Participants in the group with one or two MetS components were more likely to have a greater age, BMI, DBP, height, waist, weight, rate of obesity, FG and TG level, and a lower HDL-C level, compared with the non-MetS components group. The waist circumference, concentrations of $\mathrm{FG}$ and $\mathrm{Cu}$, the $\mathrm{Cu} / \mathrm{Zn}$ ratio and obesity rate were significantly higher in the group with three MetS components compared with groups exhibiting one, two or no MetS components.

\begin{tabular}{|c|c|c|c|c|c|c|}
\hline \multirow[t]{2}{*}{ Indexes } & \multirow{2}{*}{$\begin{array}{c}\text { Total } \\
\square \mathrm{N}=911)\end{array}$} & \multirow{2}{*}{$\begin{array}{c}\text { Male } \\
\square N=467)\end{array}$} & \multirow{2}{*}{$\begin{array}{c}\text { Female } \\
\square \mathrm{N}=444)\end{array}$} & \multicolumn{3}{|c|}{ CVD risk factors } \\
\hline & & & & $0 \square \mathrm{N}=497)$ & $10 \mathrm{~N}=336)$ & $\geq 2 \square \mathrm{N}=78)$ \\
\hline Age(years) & $9.12 \pm 1.7$ & $9.01 \pm 1.7$ & $9.23 \pm 1.7$ & $8.93 \pm 1.69$ & $9.31 \pm 1.68$ & $9.51 \pm 1.68^{\#}$ \\
\hline Height(m) & $131.52 \pm 11.84$ & $131.06 \pm 11.4$ & $132.01 \pm 12.27$ & $130.08 \pm 10.71$ & $132.71 \pm 12.58$ & $135.59 \pm 13.87^{\#}$ \\
\hline Weight(kg) & $28.95 \pm 8.74$ & $29.17 \pm 8.96$ & $28.71 \pm 8.49$ & $26.95 \pm 6.81$ & $30.33 \pm 9.27$ & $35.74 \pm 12.21^{\#}$ \\
\hline Waist(cm) & $55.96 \pm 7.91$ & $56.76 \pm 7.93$ & $55.11 \pm 7.82^{*}$ & $53.40 \pm 5.01$ & $57.58 \pm 8.69$ & $65.25 \pm 10.41^{\#}$ \\
\hline $\mathrm{BMI}(\mathrm{kg} / \mathrm{m} 2)$ & $16.41 \pm 2.78$ & $16.66 \pm 2.98$ & $16.15 \pm 2.53$ & $15.72 \pm 2.27$ & $16.86 \pm 2.82$ & $18.92 \pm 3.65^{\#}$ \\
\hline Obesity(\%) & $16.02 \%$ & $14.56 \%$ & $17.56 \%$ & $0 \%$ & $27.08 \%$ & $70.51 \%{ }^{\#}$ \\
\hline $\mathrm{TG}(\mathrm{mmol} / \mathrm{L})$ & $0.79 \pm 0.48$ & $0.74 \pm 0.46$ & $0.85 \pm 0.5^{*}$ & $0.67 \pm 0.29$ & $0.93 \pm 0.62$ & $1.00 \pm 0.56^{\#}$ \\
\hline $\begin{array}{c}\text { HDL-C } \\
(\mathrm{mmol} / \mathrm{L})\end{array}$ & $1.27 \pm 0.3$ & $1.31 \pm 0.3$ & $1.23 \pm 0.29 *$ & $1.40 \pm 0.26$ & $1.15 \pm 0.28$ & $1.01 \pm 0.21^{\#}$ \\
\hline $\mathrm{FG}(\mathrm{mmol} / \mathrm{L})$ & $4.85 \pm 0.71$ & $4.9 \pm 0.73$ & $4.8 \pm 0.68$ & $4.71 \pm 0.53$ & $4.94 \pm 0.77$ & $5.36 \pm 1.08^{\#}$ \\
\hline $\mathrm{SBP}(\mathrm{mmHg})$ & $92.44 \pm 11.42$ & $92.68 \pm 10.88$ & $92.19 \pm 11.96$ & $91.44 \pm 10.16$ & $92.92 \pm 12.31$ & $96.77 \pm 13.73^{\#}$ \\
\hline $\mathrm{DBP}(\mathrm{mmHg})$ & $60.23 \pm 8.65$ & $60.23 \pm 8.07$ & $60.23 \pm 9.24$ & $59.41 \pm 7.72$ & $60.77 \pm 9.47$ & $63.18 \pm 9.77^{\#}$ \\
\hline $\mathrm{Cu}(\mathrm{mg} / \mathrm{L})$ & $1.01 \pm 0.13$ & $1.03 \pm 0.14$ & $0.99 \pm 0.13^{*}$ & $1.00 \pm 0.13$ & $1.01 \pm 0.13$ & $1.07 \pm 0.14^{\#}$ \\
\hline $\mathrm{Zn}(\mathrm{mg} / \mathrm{L})$ & $5.21 \pm 1.07$ & $5.19 \pm 1.06$ & $5.24 \pm 1.08$ & $5.21 \pm 1.05$ & $5.22 \pm 1.09$ & $5.19 \pm 1.11$ \\
\hline $\mathrm{Cu} / \mathrm{Zn}$ & $0.2 \pm 0.05$ & $0.20 \pm 0.05$ & $0.20 \pm 0.04^{*}$ & $0.20 \pm 0.04$ & $0.20 \pm 0.05$ & $0.21 \pm 0.04^{\#}$ \\
\hline $\mathrm{Mg}(\mathrm{mg} / \mathrm{L})$ & $41.44 \pm 5.28$ & $41.29 \pm 5.24$ & $41.6 \pm 5.32$ & $41.16 \pm 5.26$ & $41.74 \pm 5.34$ & $41.92 \pm 5.04$ \\
\hline
\end{tabular}

Table 1 Basic characteristics of subjects according to gender and the number of MetS components.

BMI, body mass index; CVD, cardiovascular disease; DBP, diastolic blood pressure; FG, fasting glucose; HDL-C, high density lipoprotein-cholesterol; MetS, metabolic syndrome; SBP, systolic blood pressure; TG, triglycerides;*, p <0.05 
for gender; \#, p < 0.05 for trend; a, compared with the non-MetS component group; b, compared with the one MetS component group; c, compared with the two MetS component group.

\subsection{The association between tertiles of $\mathrm{Cu}, \mathrm{Zn}, \mathrm{Cu} / \mathrm{Zn}$ and $\mathrm{Mg}$ and MetS component indicators}

The relationships between $\mathrm{Cu}, \mathrm{Zn}, \mathrm{Cu} / \mathrm{Zn}$ and $\mathrm{Mg}$ and MetS component indicators are shown in Table 2. The values of BMI, DBP and waist circumference tended to be higher in the upper tertiles of $\mathrm{Cu}$, whereas the TG value was lowest in the third tertile of $\mathrm{Cu}$. For blood Zn, both DBP and SBP had an ascending trend with increasing tertiles of $\mathrm{Zn}$ levels. But in the $\mathrm{Cu} / \mathrm{Zn}$ group, the trend was opposite, with the values of DBP, SBP and TG decreased as Cu/Zn tertiles increased. In the Mg group, there was a significantly ascending trend for DBP, FG and TG values as the Mg tertiles increased. We also assessed the correlation between metals and MetS component indicators. Whole blood Cu was positively associated with DBP and waist circumference, and negatively associated with TG. There were positive correlations between $\mathrm{Zn}$ and FG, TG, DBP and SBP. In contrast to the Cu correlations, the ratio of $\mathrm{Cu}$ to $\mathrm{Zn}$ was negatively correlated to DBP, SBP and TG. However, waist circumference was also positively associated with the $\mathrm{Cu} / \mathrm{Zn}$ ratio. Blood Mg levels showed a correlation only with DBP.

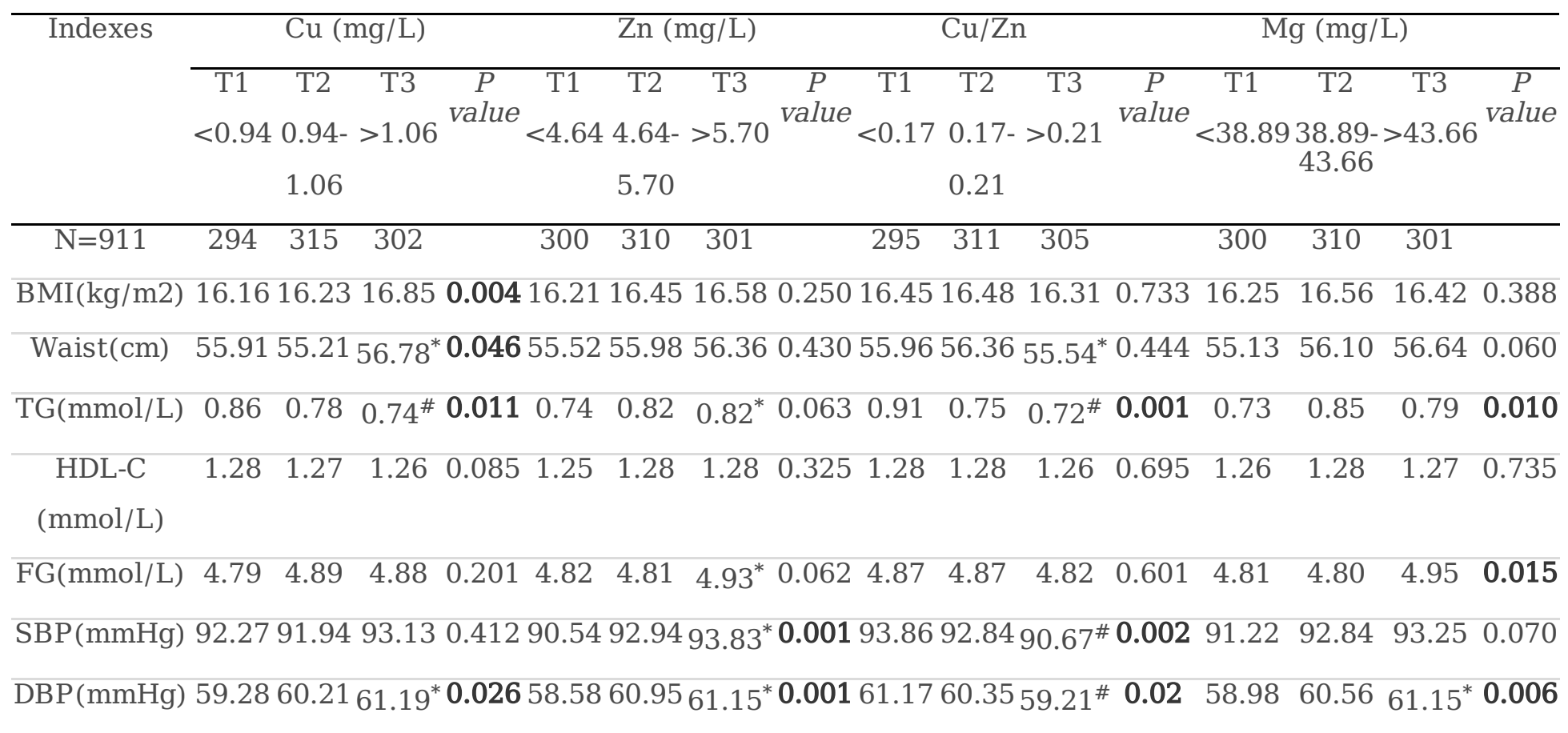

Table 2. Distribution of metabolic syndrome component indicators by tertiles (T1-T3) of blood copper (Cu), zinc $(\mathrm{Zn})$, the $\mathrm{Cu} / \mathrm{Zn}$ ratio and magnesium $(\mathrm{Mg})$ levels.

BMI, body mass index; DBP, diastolic blood pressure; FG, fasting glucose; HDL-C, high density lipoprotein-cholesterol; SBP, systolic blood pressure; TG, triglycerides; ${ }^{*}$, positive correlation; ${ }^{*}$, negative correlation.

\subsection{Odds ratios for MetS components in tertiles of $\mathrm{Cu}, \mathrm{Zn}, \mathrm{Cu} / \mathrm{Zn}$ and $\mathrm{Mg}$.}

Table 3 summarizes the ORs and $95 \%$ Cls for MetS components associated with concentrations of whole blood $\mathrm{Cu}, \mathrm{Mg}$ and $\mathrm{Zn}$, and the $\mathrm{Cu} / \mathrm{Zn}$ ratio, each categorized into tertiles. For elevated waist circumference 
measurements, significant associations were found for $\mathrm{Cu}$ and $\mathrm{Cu} / \mathrm{Zn}$ using a crude model. After adjusting for age, $\mathrm{BMI}$ and gender, the multivariable adjusted ORs $(95 \% \mathrm{Cls})$ were $2.00(1.56-3.89)$ for $\mathrm{Cu}$ and 2.08 (1.22-3.55) for $\mathrm{Cu} / \mathrm{Zn}$. No significant correlations were found between $\mathrm{Mg}$ or $\mathrm{Zn}$ and the incidence of elevated waist circumference. All of the metals were associated with the risk of incidence for elevated TG, either in the crude or adjusted model. The risk of elevated TG was significantly decreased in the tertile 3 group compared with the tertile 1 (T1) group for $\mathrm{Cu}$ and $\mathrm{Cu} / \mathrm{Zn}$ values. The ORs and $95 \% \mathrm{Cls}$ for $\mathrm{Cu}$ and $\mathrm{Cu} / \mathrm{Zn}$ were $0.34(0.17-0.66)$ and 0.31 (0.15-0.62), respectively, in the crude model. These trends persisted after adjustment, with $\mathrm{Cu}$ and $\mathrm{Cu} / \mathrm{Zn}$ showing ORs $(95 \% \mathrm{Cl})$ of $0.33(0.16-0.65)$ and 0.35 (0.17-0.71), respectively. However, TG levels were inversely associated with $\mathrm{Mg}$ and $\mathrm{Zn}$. The ORs $(95 \% \mathrm{Cl})$ for elevated TG in individuals categorized in the Mg and $\mathrm{Zn}$ tertile 2 (T2) groups were 2.36 (1.20-4.62) and 2.27 (1.18-4.35), respectively, without adjustment. The ORs ( $95 \% \mathrm{Cls})$ were attenuated but remained statistically significant after adjustment [T2 vs. T1: 2.12 (1.10-4.10) for Zn, 2.34 (1.19-4.61) for Mg]. There was no significant association between metals and hypertension, reduced HDL-C and hyperglycemia. 


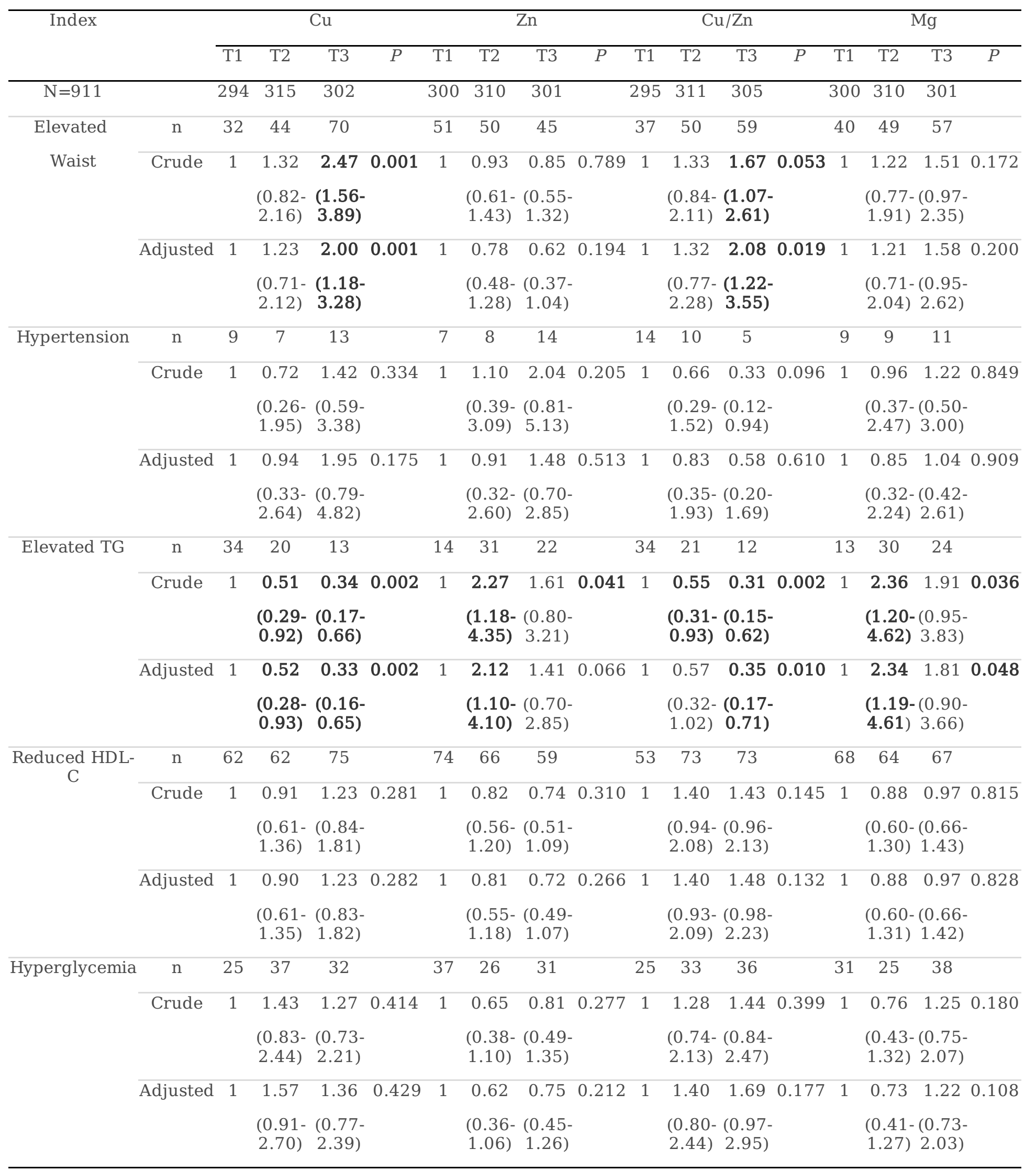

Table 3. Odds ratios ( $95 \%$ confidence intervals) for metabolic syndrome components according to whole blood metals.

Adjusted $=$ adjusted for age, BMI, gender; Crude $=$ non-adjusted; HDL-C, high density lipoprotein-cholesterol; $P, P$ for trend; TG, triglycerides; T, tertile. 


\subsection{Odds ratios for MetS components associated with tertiles of the combination of metals.}

As the metals were all associated with MetS components, we combined each of them in pairs(Cu with $\mathrm{Zn}$, $\mathrm{Cu}$ with $\mathrm{Mg}, \mathrm{Zn}$ with $\mathrm{Mg}$ ) to investigate joint correlations . In the joint analysis of $\mathrm{Cu}$ and $\mathrm{Zn}$, the combination of low $\mathrm{Cu}$ and high $\mathrm{Zn}$ increased the risk of incidence for elevated TG [OR $(95 \% \mathrm{Cl}), 2.21$ $(1.18-4.13)]$, when compared with the joint analysis of low $\mathrm{Cu}$ and low $\mathrm{Zn}$. There was no significant association between MetS components and other $\mathrm{Cu}$ and $\mathrm{Zn}$ combinations. Correlations were also observed when we considered the interaction of $\mathrm{Cu}$ and $\mathrm{Mg}$ with MetS components. High $\mathrm{Cu}$ and high $\mathrm{Mg}$ were associated with an increased risk of elevated waist circumference [OR (95\% Cl), $2.03(1.26-3.27)$ ]. But when high $\mathrm{Cu}$ was combined with low Mg, the risk of elevated TG was attenuated to 0.40 (0.160.95). In the joint analysis of $\mathrm{Zn}$ and $\mathrm{Mg}$, a significant correlation was only found for reduced HDL-C. We observed a negative association between reduced HDL-C and high Zn with low $\mathrm{Mg}$. There was no association between the combination of $\mathrm{Mg}$ and $\mathrm{Zn}$ and other MetS components.

\section{Discussion}

In this study, we explored whether the level of metals within normal reference ranges would affect the risk of metabolic syndrome components. The present findings provide evidence that whole blood Cu levels and the ratio of $\mathrm{Cu}$ to $\mathrm{Zn}$ were both positively associated with a higher OR of an elevated waist circumference and negatively associated with a higher OR of elevated TG either in crude or adjusted models. We also observed that whole blood $\mathrm{Mg}$ and $\mathrm{Zn}$ levels were positively associated with the risk of elevated TG. In addition, we performed multi-element joint analysis. Considering the interaction of metals, high $\mathrm{Cu}$ with high $\mathrm{Mg}$ was positively associated with the risk of an elevated waist circumference.

Exposure to low levels of $\mathrm{Cu}$ and high level of $\mathrm{Zn}$ further increased the risk of elevated TG compared with the other combinations of levels of these two metals, whereas a low level of $\mathrm{Cu}$ and high level of $\mathrm{Mg}$ was inversely associated with elevated TG. The combination of high $\mathrm{Zn}$ and low $\mathrm{Mg}$ was also negatively associated with the risk of reduced HDL-C levels.

In our study population, we assessed both the single and combined effects of $\mathrm{Cu}$ and $\mathrm{Zn}$ on MetS components. It was first recognized by Hart et al. [18] in 1928 that $\mathrm{Cu}$ is an essential metal for normal growth and development as an electron transfer intermediate in redox reactions [19]. Copper has a high level of oxidation and may lead to excessive damaging reactive oxygen species (ROS) by redox reactions [20] as an essential cofactor in oxidative and reductase enzymes[21]. Zinc is an integral component of a large number of proteins and enzymes, taking part in a variety of metabolic processes. Some research indicated that $\mathrm{Zn}$ overload would lead to Cu deficiency and reduced HDL-C levels [22]. As a consequence, the interaction of $\mathrm{Cu}$ and $\mathrm{Zn}$ should not be mutually exclusive, as they act as residual confounding factors for each other. This suggests that we need to reconsider previous analysis of single elements and consider interactions among these metals.

In our study, whole blood concentrations of $\mathrm{Cu}$ and $\mathrm{Zn}$ were all in the normal range $(0.61-1.9 \mathrm{mg} / \mathrm{L} \mathrm{Cu}$, 3.1-9.8 $\mathrm{mg} / \mathrm{L} \mathrm{Zn)}$, referring to a study of Swedish adolescents [23]. We observed that a higher level of 
whole blood Cu within the normal range leads to an increased risk of elevated waist circumference, which was representative of obesity. In agreement with our results, Catherine et al. [24] observed a positive relationship between serum $\mathrm{Cu}$ and abdominal obesity. We also observed that the risk of elevated TG was decreased with ascending tertiles of $\mathrm{Cu}$. It is established that $\mathrm{Cu}$ has affects lipid metabolism, but the reported effects of $\mathrm{Cu}$ on each index of lipid metabolism remains inconsistent. Some studies suggested that serum Cu levels were positively associated with total cholesterol, TG or low density lipoprotein, such as those examining 15-80-year-old Kuwaiti people [25] and young American adults [26]. But in the National Health and Nutrition Examination Survey, 2011-2014, there were no associations between serum $\mathrm{Cu}$ and TG levels in children and adolescents [27]. In contrast, Leslie et al. [28] reported that increased total cholesterol and reduced HDL-C levels were observed in subjects with low Cu levels, consistent with our results.

In the current study, although the concentration of $\mathrm{Zn}$ was in the normal range, we observed that tertiles of $\mathrm{Zn}$ were positively associated with the risk of elevated TG, in agreement with studies of Tehran's urban population $(O R=1.60)$ [29] and Korean adults $(O R=1.47)$ [30]. Sukalski et al. found that a reduced serum $\mathrm{Cu}$ concentration leads to reduced $\mathrm{Cu} / \mathrm{Zn}$ superoxide dismutase activity [31]. The $\mathrm{Cu} / \mathrm{Zn}$ ratio can be used to determine the level of oxidative stress. In this study, all the values of $\mathrm{Cu} / \mathrm{Zn}$ were less than 1.0, indicating the antioxidant mechanism in this population was normal [32]. In addition, the correlations of $\mathrm{Cu} / \mathrm{Zn}$ with elevated waist circumference and elevated TG were consistent with the correlations found with $\mathrm{Cu}$, and with the findings reported by Fedor et al. [33]. In our investigation of the combination of $\mathrm{Cu}$ and $\mathrm{Zn}$, we found a low level of Cu combined with a high level of $\mathrm{Zn}$ was positively associated with the risk of elevated TG, suggesting the combination of these two metals regulate TG levels.

Magnesium is also a coenzyme factor that affects the metabolism of glucose and lipids. Unlike some reports indicating that $\mathrm{Mg}$ supplements reduced TG levels and blood pressure [34], we observed an increased risk of elevated TG with the second tertile of $\mathrm{Mg}$. Other studies suggested that $\mathrm{Mg}$ supplements were negatively associated with the risk of MetS [35,36], so it is possible that low levels of Mg may be associated with the incidence of some MetS components. In the current study, the incidence of reduced HDL-C was increased by the combination of a high Zn level and a low Mg level. There was a significant association between a high Cu level combined with a low Mg level and the risk of elevated TG, which was consistent with the function of single metals. When $\mathrm{Cu}$ and $\mathrm{Mg}$ were both at high levels, the risk of an elevated waist circumference was raised. This was in agreement with a cross-sectional study conducted by Beydoun et al. [37].

The current study has several strengths. This is the first study to assess the relationship between all of the key MetS components and $\mathrm{Cu}, \mathrm{Mg}$ and $\mathrm{Zn}$, both individually and combined, among Chinese rural children with associated CNNS data. The study population has a rural national representation. In addition, this study evaluated biological associations with metal levels in whole blood samples, rather than commonly used plasma and serum samples. Some studies showed that whole blood can more comprehensively reflect the long-term status of metals in the body, and may not be markedly affected by current dietary intake $[38,39]$. Moreover, this study considered the interaction between elements, and 
provided the analysis of single elements, as well as the combined action of multiple metals. Our current findings provide the foundation for future research on the combined use of multiple elements. Another strength of this study was the findings for 6-12-year-old children in rural China. Although the relationship of MetS in children and adolescents has attracted more attention in recent years, there are still few studies involving such a low age group.

Several limitations of our study need to be considered. First, the physiological functions of $\mathrm{Cu}$ and $\mathrm{Zn}$ may influence the process of inflammation. However, we could not adjust for inflammatory indicators, such as C-reaction protein, as confounding factors in the analysis because such factors were not measured in this study. Second, this study lacked analysis of dietary factors, which have a great influence upon these metals. Thus, we could only obtain long-term associations between these three metals, and not a generalized and comprehensive correlation between $\mathrm{Cu}, \mathrm{Mg}$ and $\mathrm{Zn}$, and MetS components. Because of the relatively small age of the sample population, the prevalence of MetS was also very low, so we investigated the relationship between the metals and components of MetS.

\section{Conclusions}

Higher levels of whole blood $\mathrm{Cu}$ and $\mathrm{Cu} / \mathrm{Zn}$ were positively associated with the risk of an elevated waist circumference and negatively associated with the risk of elevated TG. Additionally, higher $\mathrm{Zn}$ and $\mathrm{Mg}$ levels increased the risk of elevated TG levels. The combination of two metals may provide guidance to regulate the conditions of elevated waist circumference, elevated TG and reduced HDL-C levels. In future research, we will conduct a prospective cohort and include dietary and genetic factors to better understand the relationship between trace elements and MetS.

\section{List Of Abbreviations}

MetS: metabolic syndrome; AAP:American Academy of Pediatrics; IDF:International Diabetes Federation; $\mathrm{BMI}$, body mass index; TG, triglycerides; HDL-C,high density lipoprotein cholesterol;FG, fasting glucose; SBP,systolic blood pressure; DBP, diastolic blood pressure;

\section{Declarations}

\section{Ethics approval and consent to participate}

The study was conducted in accordance with the Declaration of Helsinki, and the protocol was approved by the Ethics Committee of Institute for Nutrition and Food Safety, China CDC (now change to National Institute for Nutrition and Health, China CDC) (file number 2013-018).

\section{Consent for publication}

The authors consent to the publication of the data. 
Availability of data and materials

The datasets used or analysed during the current study are available from the corresponding author Lichen Yang on reasonable request.

\section{Competing interests}

The authors declare that they have no competing interests.

Funding: This research received no external funding.

\section{Author Contributions}

H.Z. and Q.M. wrote the paper and analyzed data; P.S.,S.L, and Y.Q. provided essential materials; X.L.conducted research; L.W. performed statistical analysis; L.Y. designed research and had primary responsibility for final content. All authors read and approved the final manuscript.

Acknowledgments: This research was supported by the Major program for health care reform from Chinese National Health and Family Planning Commission. We are grateful to all the participants in our study and all the staff working for the China National Nutrition and Health Survey 2010-2012 (CNNS2010-2012).

\section{References}

1. Alberti K G M M,Eckel Robert H,Grundy Scott M et al. Harmonizing the metabolic syndrome: a joint interim statement of the International Diabetes Federation Task Force on Epidemiology and Prevention; National Heart, Lung, and Blood Institute; American Heart Association; World Heart Federation; International Atherosclerosis Society; and International Association for the Study of Obesity.[J] .Circulation, 2009, 120: 1640-5.

2. Lu Jieli,Wang Limin,Li Mian et al. Metabolic Syndrome Among Adults in China: The 2010 China Noncommunicable Disease Surveillance.[J] .J. Clin. Endocrinol. Metab., 2017, 102: 507-515.

3. Ye Peiyu,Yan Yinkun,Ding Wenqing et al. [Prevalence of metabolic syndrome in Chinese children and adolescents: a Meta-analysis].[J] .Zhonghua Liu Xing Bing Xue Za Zhi, 2015, 36: 884-8.

[4]Lars Friberg, Gunnar F. Nordberg and Velimir B. Vouk. Hand book on the toxicology of metals: Edited by Elsevier/North Holland, Amsterdam. 1979. Pp. 709.

[5]Yuan Yu,Xiao Yang,Yu Yanqiu et al. Associations of multiple plasma metals with incident type 2 diabetes in Chinese adults: The Dongfeng-Tongji Cohort.[J] .Environ. Pollut., 2018, 237: 917-925.

[6]Olechnowicz J,Tinkov A,Skalny A et al. Zinc status is associated with inflammation, oxidative stress, lipid, and glucose metabolism.[J] .J Physiol Sci, 2018, 68: 19-31. 
[7]Bo Simona,Durazzo Marilena,Gambino Roberto et al. Associations of dietary and serum copper with inflammation, oxidative stress, and metabolic variables in adults.[J] .J. Nutr., 2008, 138: 305-10.

[8]Klotz Lars-Oliver,Kröncke Klaus-Dietrich,Buchczyk Darius P et al. Role of copper, zinc, selenium and tellurium in the cellular defense against oxidative and nitrosative stress.[J] .J. Nutr., 2003, 133: 1448S-51S

[9]Zhao Binghao,Deng Huan,Li Bo et al. Association of magnesium consumption with type 2 diabetes and glucose metabolism: A systematic review and pooled study with trial sequential analysis.[J] .Diabetes Metab. Res. Rev., 2020, 36: e3243.

[10]Carrier Alice,Metabolic Syndrome and Oxidative Stress: A Complex Relationship.[J] .Antioxid. Redox Signal., 2017, 26: 429-431.

[11]Freitas Erika P S,Cunha Aline T O,Aquino Sephora L S et al. Zinc Status Biomarkers and Cardiometabolic Risk Factors in Metabolic Syndrome: A Case Control Study.[J] .Nutrients, 2017, 9: undefined.

[12]Qu Rongge,Jia Yubing,Liu Junyi et al. Dietary Flavonoids, Copper Intake, and Risk of Metabolic Syndrome in Chinese Adults.[J] .Nutrients, 2018, 10: undefined.

[13]La Sang A,Lee June Young,Kim Do Hoon et al. Low Magnesium Levels in Adults with Metabolic Syndrome: a Meta-Analysis.[J] .Biol Trace Elem Res, 2016, 170: 33-42.

[14]Mortazavi Smj,Mortazavi Ghazal,Paknahad Maryam,Levels of arsenic, mercury, cadmium, copper, lead, zinc, and manganese in serum and whole blood of resident adults from mining and non-mining communities in Ghana.[J] .Environ Sci Pollut Res Int, 2016, 23: 22220-22221.

[15]Schultze Björn,Lind P Monica,Larsson Anders et al. Whole blood and serum concentrations of metals in a Swedish population-based sample.[J] .Scand. J. Clin. Lab. Invest., 2014, 74: 143-8.

[16]Green S B,How Many Subjects Does It Take To Do A Regression Analysis.[J] .Multivariate Behav Res, 1991, 26: 499-510.

[17]Zimmet P, Alberti KG, Kaufman F, et al; IDF Consensus Group. The metabolic

syndrome in children and adolescents - an IDF consensus report. Pediatr Diabetes. 2007;8(5):299-306

[18]Hart E B,Steenbock H,Waddell J et al. Iron in nutrition. VII. Copper as a supplement to iron for hemoglobin building in the rat. 1928.[J] .J. Biol. Chem., 2002, 277: e22.

[19]Yin Jiawei,Wang Xiaoqian,Li Shuzhen et al. Interactions between plasma copper concentrations and SOD1 gene polymorphism for impaired glucose regulation and type 2 diabetes.[J] .Redox Biol, 2019, 24: 101172. 
[20]Kaler Stephen G,ATP7A-related copper transport diseases-emerging concepts and future trends.[J] .Nat Rev Neurol, 2011, 7: 15-29.

[21]Uauy R,Olivares M,Gonzalez M,Essentiality of copper in humans.[J] .Am. J. Clin. Nutr., 1998, 67: 952S959S.

[22]Cai Lu,Li Xiao-Kun,Song Ye et al. Essentiality, toxicology and chelation therapy of zinc and copper.[J] .Curr. Med. Chem., 2005, 12: 2753-63.

[23]Bárány Ebba,Bergdahl Ingvar A,Bratteby Lars-Eric et al. Trace element levels in whole blood and serum from Swedish adolescents.[J] .Sci. Total Environ., 2002, 286: 129-41.

[24]Bulka Catherine M,Persky Victoria W,Daviglus Martha L et al. Multiple metal exposures and metabolic syndrome: A cross-sectional analysis of the National Health and Nutrition Examination Survey 20112014.[J] .Environ. Res., 2019, 168: 397-405.

[25]Abiaka Clifford,Olusi Samuel,Al-Awadhi Adel,Serum microminerals and the indices of lipid metabolism in an apparently healthy population.[J] .J. Clin. Lab. Anal., 2003, 17: 61-5.

[26]Medeiros D,Pellum L,Brown B,Serum lipids and glucose as associated with hemoglobin levels and copper and zinc intake in young adults.[J] .Life Sci., 1983, 32: 1897-904.

[27]Fan Yun,Zhang Chunlan,Bu Jin,Relationship between Selected Serum Metallic Elements and Obesity in Children and Adolescent in the U.S.[J] .Nutrients, 2017, 9: undefined.

[28]Klevay, L.M., et al., Increased cholesterol in plasma in a young man during experimental copper depletion. Metabolism: clinical and experimental, 1984.33(12): p. 1112-1118.

[29]Ghasemi Asghar,Zahediasl Saleh,Hosseini-Esfahani Firoozeh et al. Gender differences in the relationship between serum zinc concentration and metabolic syndrome.[J] .Ann. Hum. Biol., 2014, 41: 436-42.

[30]Seo Jin-A,Song Sang-Wook,Han Kyungdo et al. The associations between serum zinc levels and metabolic syndrome in the Korean population: findings from the 2010 Korean National Health and Nutrition Examination Survey.[J] .PLoS ONE, 2014, 9: e105990.

[31]Sukalski K A,LaBerge T P,Johnson W T,In vivo oxidative modification of erythrocyte membrane proteins in copper deficiency.[J] .Free Radic. Biol. Med., 1997, 22: 835-42.

[32]Inutsuka S,Araki S,Plasma copper and zinc levels in patients with malignant tumors of digestive organs: clinical evaluation of the $\mathrm{Cu} / \mathrm{Zn}$ ratio.[J] .Cancer, 1978, 42: 626-31.

[33]Serum Concentration of Zinc, Copper, Selenium, Manganese, and Cu/Zn Ratio in Children and Adolescents with Myopia.[J] .Biol Trace Elem Res, 2017, 176: 1-9 
[34]Singh R B,Rastogi S S,Mani U V et al. Does dietary magnesium modulate blood lipids?[J].Biol Trace Elem Res, 1991, 30: 59-64.

[35]Ju Sang-Yhun,Choi Whan-Seok,Ock Sun-Myeong et al. Dietary magnesium intake and metabolic syndrome in the adult population: dose-response meta-analysis and meta-regression.[J] .Nutrients, 2014, 6: 6005-19.

[36]Dibaba D T,Xun P,Fly A D et al. Dietary magnesium intake and risk of metabolic syndrome: a metaanalysis.[J] .Diabet. Med., 2014, 31: 1301-9.

[37]Beydoun May A,Gary Tiffany L,Caballero Benjamin $\mathrm{H}$ et al. Ethnic differences in dairy and related nutrient consumption among US adults and their association with obesity, central obesity, and the metabolic syndrome.[J] .Am. J. Clin. Nutr., 2008, 87: 1914-25.

[38]Saleh Farid,Behbehani Abdallah,Asfar Sami et al. Abnormal blood levels of trace elements and metals, DNA damage, and breast cancer in the state of Kuwait.[J] .Biol Trace Elem Res, 2011, 141: 96-109.

[39]Zabłocka-Słowińska Katarzyna,Płaczkowska Sylwia,Prescha Anna et al. Serum and whole blood Zn, $\mathrm{Cu}$ and $\mathrm{Mn}$ profiles and their relation to redox status in lung cancer patients.[J] .J Trace Elem Med Biol, 2018, 45: 78-84.

\section{Figures}

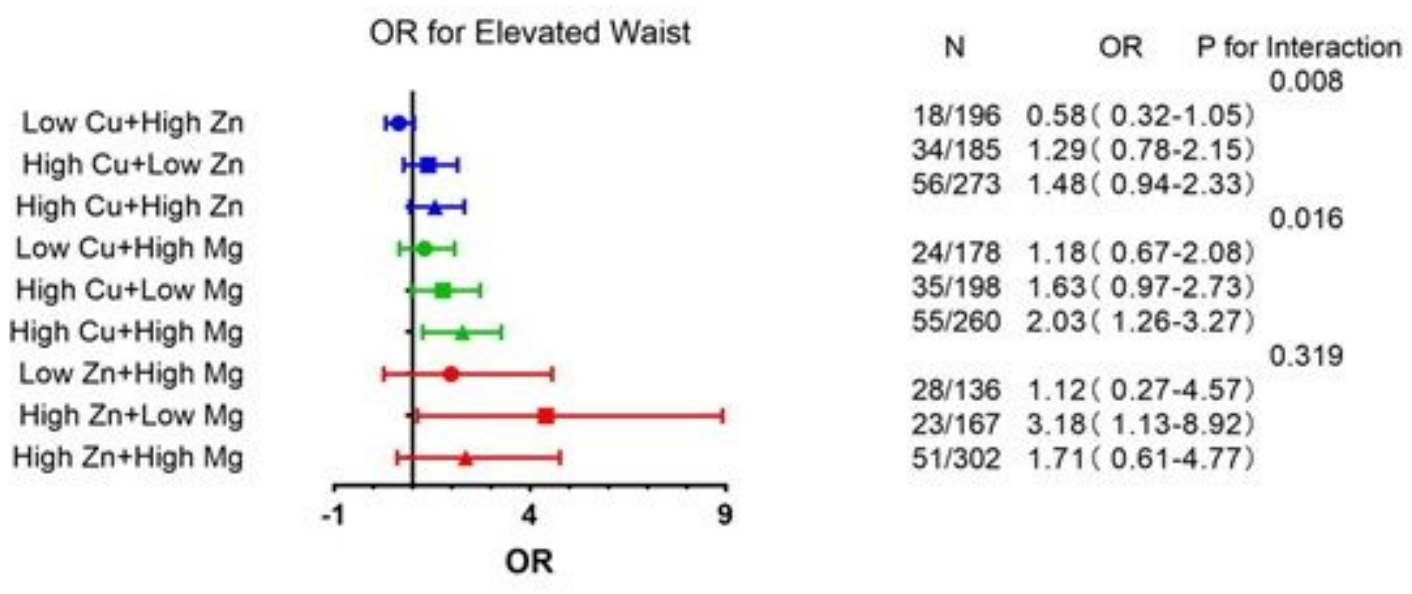

\section{Figure 1}

Associations of blood element levels with elevated waist circumference. HDL-C, high density lipoproteincholesterol; TG, triglycerides; Low means $<50 \%$ concentration; High means $\geq 50 \%$ concentration; Low Cu+ Low Zn,Low Cu+ Low Mg and Low Zn+ Low Mg were taken as the reference; Shown are the odds ratios (ORs) and $95 \%$ confidence intervals in parentheses. 


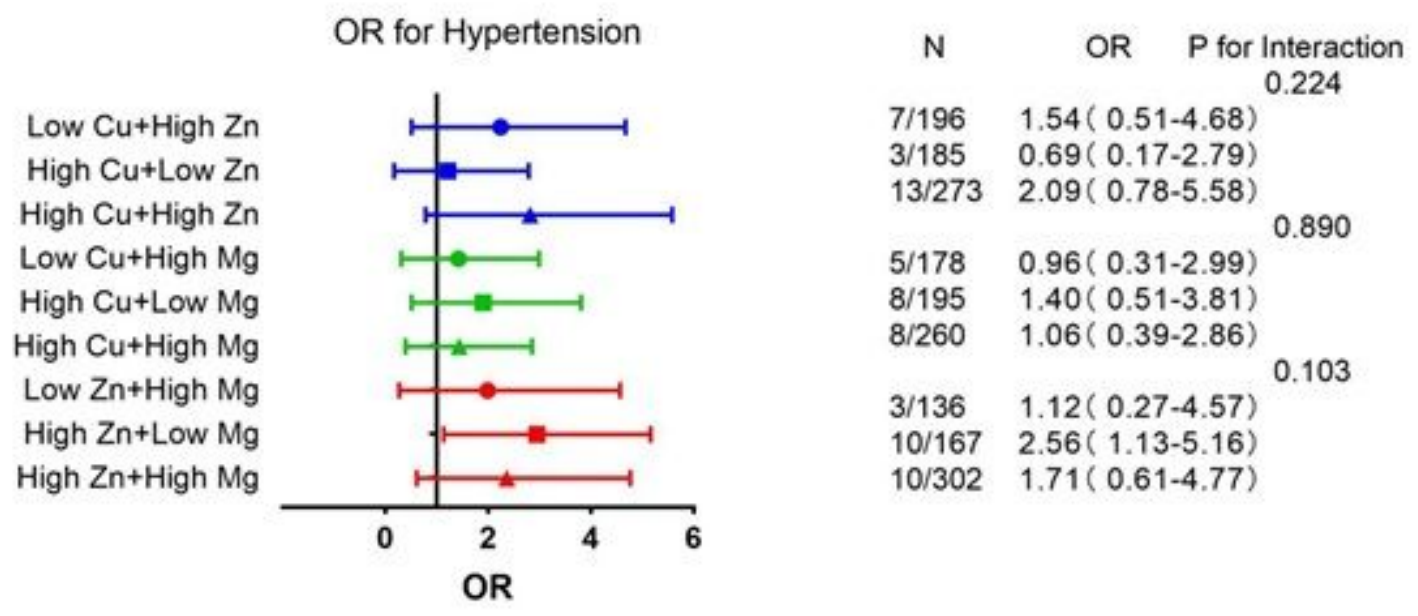

\section{Figure 2}

Associations of blood element levels with hypertension. HDL-C, high density lipoprotein-cholesterol; TG, triglycerides; Low means $<50 \%$ concentration; High means $\geq 50 \%$ concentration; Low Cu+ Low Zn,Low $\mathrm{Cu}+\mathrm{Low} \mathrm{Mg}$ and Low $\mathrm{Zn}+$ Low Mg were taken as the reference; Shown are the odds ratios (ORs) and $95 \%$ confidence intervals in parentheses.

OR for Elevated TG

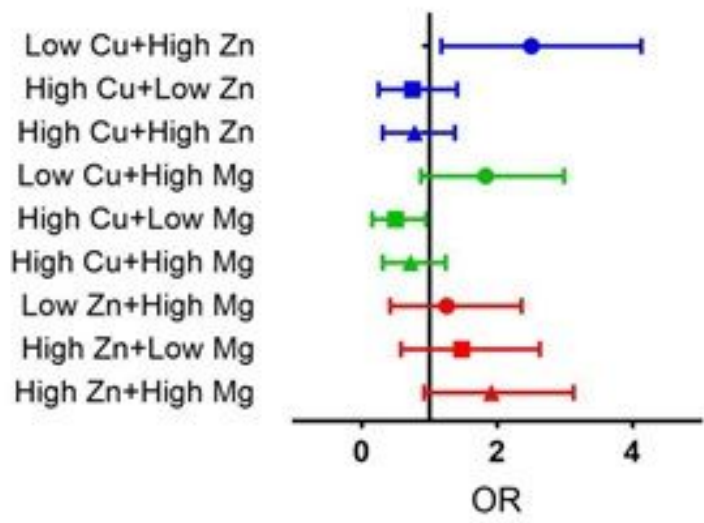

\begin{tabular}{lcc}
\multicolumn{1}{c}{$N$} & \multicolumn{1}{c}{ OR $\quad P$ for Interaction } \\
& \multicolumn{2}{c}{0.001} \\
$28 / 196$ & $2.21(1.18-4.13)$ & \\
$8 / 185$ & $0.60(0.25-1.41)$ & \\
$13 / 273$ & $0.66(0.31-1.38)$ & 0.003 \\
& & 0.003 \\
$23 / 178$ & $1.62(0.88-2.99)$ & \\
$7 / 195$ & $0.40(0.16-0.95)$ & \\
$14 / 260$ & $0.62(0.31-1.24)$ & 0.301 \\
& & \\
$8 / 136$ & $1.00(0.42-2.36)$ & \\
$12 / 167$ & $1.23(0.58-2.63)$ & \\
$29 / 302$ & $1.70(0.92-3.13)$ &
\end{tabular}

\section{Figure 3}

Associations of blood element levels with elevated triglycerides. HDL-C, high density lipoproteincholesterol; TG, triglycerides; Low means $<50 \%$ concentration; High means $\geq 50 \%$ concentration; Low Cu+ Low Zn,Low Cu+ Low Mg and Low Zn+ Low Mg were taken as the reference; Shown are the odds ratios (ORs) and 95\% confidence intervals in parentheses. 
OR for Reduced HDL-C

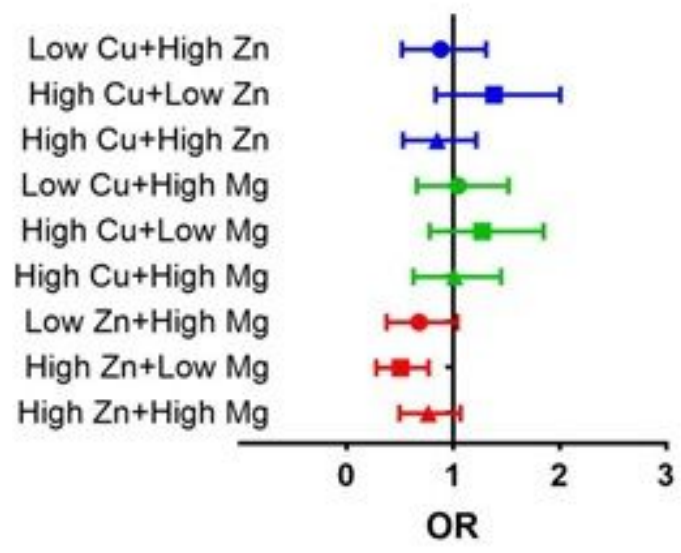

N OR P for Interaction

$38 / 196 \quad 0.82(0.52-1.31)^{0.134}$

$51 / 185 \quad 1.30(0.84-2.01)$

$52 / 273 \quad 0.80(0.53-1.22)$

$37 / 178 \quad 0.96(0.66-1.52)$

$49 / 195 \quad 1.20(0.78-1.85)$

$54 / 260 \quad 0.96(0.63-1.45)$

$26 / 136 \quad 0.63(0.38-1.04)$

$25 / 167 \quad 0.47(0.28-0.77)$

$65 / 302 \quad 0.73(0.50-1.07)$

\section{Figure 4}

Associations of blood element levels with reduced HDL-C HDL-C, high density lipoprotein-cholesterol; TG, triglycerides; Low means $<50 \%$ concentration; High means $\geq 50 \%$ concentration; Low Cu+ Low Zn,Low $\mathrm{Cu}+\mathrm{Low} \mathrm{Mg}$ and Low $\mathrm{Zn}+$ Low Mg were taken as the reference; Shown are the odds ratios (ORs) and $95 \%$ confidence intervals in parentheses.

OR for Hyperglycemia

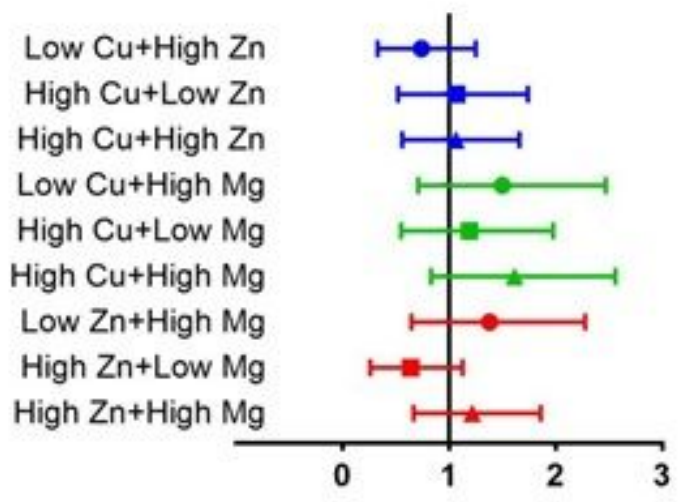

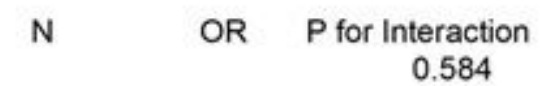

$15 / 196 \quad 0.65(0.33-1.25)$

$20 / 185 \quad 0.95(0.52-1.74)$

$30 / 273 \quad 0.97(0.56-1.66)$

$20 / 178 \quad 1.32(0.71-2.47)$

$18 / 195 \quad 1.04(0.55-1.98)$

$32 / 2601.46(0.83-2.56)$

$17 / 136 \quad 1.22(0.65-2.28)$

$10 / 167 \quad 0.54(0.26-1.13)$

$35 / 302 \quad 1.12(0.67-1.86)$
0.503

0.202

\section{Figure 5}

Associations of blood element levels with hyperglycemia. HDL-C, high density lipoprotein cholesterol; TG, triglycerides; Low means $<50 \%$ concentration; High means $\geq 50 \%$ concentration; Low Cu+ Low Zn,Low $\mathrm{Cu}+\mathrm{Low} \mathrm{Mg}$ and Low $\mathrm{Zn}+$ Low Mg were taken as the reference; Shown are the odds ratios (ORs) and $95 \%$ confidence intervals in parentheses. 